\title{
Therapeutic effect of taurine on sodium fluoride toxicity in chicks
}

\author{
E.H. Alabbasi ${ }^{1}\left(\right.$ and Y.Z. Al-Abdaly ${ }^{2}$ \\ ${ }^{1}$ Iraqi Ministry of Agriculture, Nineveh Agriculture Directorate, ${ }^{2}$ Department of Physiology, Biochemistry and Pharmacology, \\ Collage of Veterinary Medicine, University of Mosul, Mosul, Iraq
}

\begin{tabular}{l} 
Article information \\
\hline Article history: \\
Received April 01, 2021 \\
Accepted May 26, 2021 \\
Available online December 19, 2021 \\
\hline Keywords: \\
Taurine \\
Sodium fluoride \\
Neurobehavioral test \\
Chicks \\
\\
\hline Correspondence: \\
Y.Z. Al-Abdaly \\
yalabdali@ yahoo.com
\end{tabular}

\begin{abstract}
The study aimed to investigate if taurine could help reduce sodium fluoride-induced toxicity in chicks. The chicks in this study were divided into four equal groups, each with eight chicks: the control group, sodium fluoride $20 \mathrm{mg} / \mathrm{kg}$ group, taurine $3 \mathrm{~g} / \mathrm{kg}$ group, the fourth group was dosed with each of the sodium fluoride $20 \mathrm{mg} / \mathrm{kg}$ and taurine $3 \mathrm{~g} / \mathrm{kg}$ groups all groups were dosed orally. The dosing was set at 5 days/week for 4 weeks. After 2 and 4 weeks of treatment, the group treated with taurine alone or with sodium fluoride showed an improvement in neurobehavioral and motor activity, as evidenced by a reduction in the duration of chick immobility in the immobility test and an increase in the number of squares cross in the open field test compared to the group treated with sodium fluoride alone. The level of ALT enzyme and calcium in the group treated with sodium fluoride increased significantly compared to the control and taurine group alone, and with sodium fluoride, AST and creatinine levels increased significantly after 4 weeks of sodium fluoride treatment compared to the other groups. When it came to measuring malondialdehyde and glutathione, the sodium fluoride group alone showed a significant increase in malondialdehyde and significant decrease in glutathione after 2 and 4 weeks of treatment when compared to the control and the other groups. The histopathological examination confirmed the previous findings, with the histological sections of the liver, kidney, and brain showing a significant improvement in the group treated with sodium fluoride and taurine after four weeks of treatment. We conclude from this study that taurine has a clear therapeutic effect against oxidative stress, as evidenced by behavioral and motor behavioral effects, as well as levels of glutathione, malondialdehyde, and liver function enzymes, and serum creatinine, as well as histopathological examination of the brain, kidneys, and liver.
\end{abstract}

DOI: 10.33899/ijvs.2021.129854.1692, (CAuthors, 2022, College of Veterinary Medicine, University of Mosul.

This is an open access article under the CC BY 4.0 license (http://creativecommons.org/licenses/by/4.0/).

\section{Introduction}

In most mammalian tissues, taurine is the primary sulfur-containing amino acid found within cells (1). Taurine's antioxidant properties have been attributed to its ability to influence biomembrane stability, scavenge ROSfree radicals, and reduce oxidative stress damage (2).

A study on pigeons found that the amount of taurine provided during the growth period had an impact on puberty behavior in the longer term. It has been discovered that offspring improve their spatial learning abilities and their willingness to take risks (3). A zebrafish study found that taurine inhibits risk assessment behavior, which is a defense mechanism (4).

Excessive fluoride exposure causes neurotoxicity in both humans and animals, according to epidemiological and experimental studies, and one study found that taurine's antidepressant effect is mediated by increased mRNA expression in the hippocampus (5).

Through the oxidation of fats and proteins, as well as DNA damage, oxidative stress causes nerve cell damage and death (6). The liver is the main site for microorganism 
detoxification, and toxins can easily alter the metabolism process, the toxic effect of the liver is usually manifested by disturbances in cellular respiration that interfere with redox mechanisms (7).

Other studies on the catfish Heteropneustis fossils found that exposure to $35 \mathrm{mg} / \mathrm{L}$ and $70 \mathrm{mg} / \mathrm{L}$ fluorides in water for 45 and 90 days caused kidney degeneration, enlargement of renal tubule epithelial cells, and glomeruli dilation (8). glutathione is one of the most important cellular antioxidants in the liver, and its depletion decreases the cell's ability to fight free radicals and has been linked to liver injury. Cysteine can decrease oxidative stress and cell injury in alcohol-treated rats by inhibiting lipid peroxidation, according to one study. Standardize antioxidant levels as well (9).

Fluorine is a highly poisonous substance that is found in a wide range of foods and beverages. While fluorine is not naturally free, it can combine with almost all minerals and nonmetals, except oxygen and inert gases (10). Fluorine can be found in water, soil, air, nutrients, and plants, and it poses a health risk to humans and animals (11).

Despite numerous hypotheses, the exact mechanism of fluoride toxicity remains unknown. Fluoride accumulation in the body causes blood, liver, renal, and nerve diseases, according to numerous animal studies. Fluoride can also harm cells by causing protein damage and causing the formation of free radicals (12). Investigate the effects of therapeutic taurine on fluorine-induced toxicity at the level of nervous behavior and motor activity, as well as its effects on some internal organs through histopathological tissue sections, and the relationship between all of these effects and changes in the levels of some enzymes and minerals, as well as measuring glutathione and malondialdehyde levels.

\section{Materials and methods}

Experiments were carried out on the 32 chicks body weight 300-850 gram. After they had reached the age of one week and had been raised in the animal house of the University of Mosul's College of Veterinary Medicine. The tests used regular oral doses of sodium fluorid powder from BDH Small Pool in England, dilute formalin for sample preservation, and Biolabo, Biomerieux, France company kits for measuring enzymes and minerals. Taurine powder from France company dissolved in distilled water at a volume of administration is $5 \mathrm{~mL} / \mathrm{kg}$ body weight. ALT,
AST, Creatinine, $\mathrm{Ca}$, and $\mathrm{P}$ were measured using a diagnostic kit from the French company BIO LABO, glutathione was measured using the modified Allman method (13) malondialdehyde was measured using the Beuge and Aust method (14).

\section{Statistical analysis}

Mann-Whitney test was used to investigate the nonparametric findings. SPSS was used to interpret the parameterized results. Tow-way analysis, ANOVA. The findings were then put through an LSD test. All of the results had a probability level less than 0.05 .

\section{Results}

After 2 and 4 weeks of daily treatment, the group of taurine and sodium fluoride alone or together showed an improvement in neurobehavioral and motor activity, as evidenced by a reduction in the period of immobilization in chicks in the tonic immobility test compared to the group of sodium fluoride alone (Table 1). After 2 and 4 weeks of daily treatment, the group of taurine and sodium fluoride alone or together showed an increase in the number of cross squares in the open field test compared to the group of sodium fluoride alone (Table 2).

After 2 and 4 weeks of treatment, the level of the enzyme ALT increased significantly in the group of sodium fluoride compared to the control and taurine groups alone and with sodium fluoride. AST and creatinine levels increased significantly after 4 weeks of sodium fluoride treatment when compared to the other groups, the group of sodium fluoride alone showed a significant increase in calcium after 2 and 4 weeks of treatment, while phosphorus did not show a significant difference in any of the groups (Table 3).

There was a significant increase in the level of malondialdehyde after 2 and 4 weeks of treatment with sodium fluoride alone compared to the control, and after 4 weeks, there was a significant increase in the level of malondialdehyde compared to the control and the rest of the groups (Table 4). After two and four weeks, the glutathione level in the group of sodium fluoride alone decreased significantly compared to the control and the rest of the groups (Table 5).

Table 1: Tonic immobility test after 2 and 4 weeks of treatment with taurine and sodium fluoride alone or together

\begin{tabular}{lcc}
\hline Groups & Tonic immobility test after 2 weeks/s & Tonic immobility test after 4 weeks/s \\
\hline Control & $35 \pm 10$ & $40 \pm 12$ \\
Sodium fluoride $20 \mathrm{mg} / \mathrm{kg}$ & $300 \pm 60^{*}$ & $300 \pm 77^{*}$ \\
Taurine $3 \mathrm{~g} / \mathrm{kg}$ & $40.8^{ \pm} 11^{\mathrm{a}}$ & $35 \pm 10^{\mathrm{a}}$ \\
Sodium fluoride $20 \mathrm{mg} / \mathrm{kg}+$ Taurine $3 \mathrm{~g} / \mathrm{kg}$ & $38^{ \pm} 14^{\mathrm{a}}$ & $30 \pm 12^{\mathrm{a}}$ \\
\hline E &
\end{tabular}

Each group consists of 8 animals. *Represents the significant difference from the control group when $\mathrm{P}<0.05$. a, represented a significant difference from the sodium fluoride group after 2 and 4 weeks of treatment. Mean \pm standard error. 
Table 2: The open field activity after 2 and 4 weeks of taurine and sodium fluoride treatment alone or together

\begin{tabular}{lcc}
\hline Groups & $\begin{array}{c}\text { Number of squares cross } \\
\text { after 2 }\end{array}$ & $\begin{array}{c}\text { Number of squares cross } \\
\text { after 4 weeks of treatment }\end{array}$ \\
\hline Control & $6 \pm 1$ & $5 \pm 2$ \\
Sodium fluoride $20 \mathrm{mg} / \mathrm{kg}$ & $2 \pm 5^{*}$ & $1.5 \pm 1^{*}$ \\
Taurine $3 \mathrm{~g} / \mathrm{kg}$ & $7 \pm 2^{\mathrm{a}}$ & $6 \pm 1^{\mathrm{a}}$ \\
Sodium fluoride $20 \mathrm{mg} / \mathrm{kg}+$ Taurine $3 \mathrm{~g} / \mathrm{kg}$ & $4 \pm 3^{\mathrm{a}}$ & $4 \pm 2^{\mathrm{a}}$ \\
\hline
\end{tabular}

Each group consists of 8 animals. *Represents the significant difference from the control group when $\mathrm{P}<0.05$. a, represented a significant difference from the sodium fluoride group after 2 and 4 weeks of treatment. Mean \pm standard error.

Table 3: Enzyme and mineral concentrations after 2 and 4 weeks of treatment with $\mathrm{NaF}$ and taurine alone or together

\begin{tabular}{lccccc}
\hline Groups & $\begin{array}{c}\text { ALT } \\
\mathrm{U} / \mathrm{L}\end{array}$ & $\begin{array}{c}\text { AST } \\
\mathrm{U} / \mathrm{L}\end{array}$ & $\begin{array}{c}\text { Creatinine } \\
\mathrm{Mg} / \mathrm{dl}\end{array}$ & $\begin{array}{c}\text { Calcium } \\
\mathrm{mmol} / \mathrm{L}\end{array}$ & $\begin{array}{c}\text { Phosphor } \\
\mathrm{mmol} / \mathrm{L}\end{array}$ \\
\hline Control & $11 \pm 0.4$ & $162 \pm 32$ & $0.07 \pm 0.01$ & $11.9 \pm 3$ & $6.95 \pm 3$ \\
Sodium fluoride $20 \mathrm{mg} / \mathrm{kg}$ after2 week & $13 \pm 2^{*}$ & $164 \pm 43$ & $0.08 \pm 0.03^{*}$ & $10.92 \pm 2^{*}$ & $6.57 \pm 2$ \\
Sodium fluoride $20 \mathrm{mg} / \mathrm{kg}$ after4 week & $14 \pm 2^{* \mathrm{a}}$ & $596 \pm 50^{* \mathrm{aA}}$ & $0.1 \pm 0.08^{* \mathrm{aA}}$ & $9.92 \pm 2^{* \mathrm{a}}$ & $5.98 \pm 2$ \\
Taurine $3 \mathrm{~g} / \mathrm{kg}$, after 2week & $11.7 \pm 2^{\mathrm{ab}}$ & $160 \pm 28^{\mathrm{b}}$ & $0.08 \pm 0.08^{\mathrm{b}}$ & $10.8 \pm 8^{\mathrm{ab}}$ & $6.9 \pm 1$ \\
Taurine $3 \mathrm{~g} / \mathrm{kg}$, after 4week & $11.2 \pm 1.1^{\mathrm{ab}}$ & $161 \pm 52^{\mathrm{b}}$ & $0.08 \pm 0.01^{\mathrm{b}}$ & $10.5 \pm 4^{\mathrm{ab}}$ & $6.83 \pm 1$ \\
Sodium fluoride 20 mg/kg+Taurine $3 \mathrm{~g} / \mathrm{kg}$ after 2 week & $11.5 \pm 2^{\mathrm{ab}}$ & $160 \pm 22^{\mathrm{b}}$ & $0.07 \pm 0.01^{\mathrm{b}}$ & $11.0 \pm 2^{\mathrm{ab}}$ & $6.7 \pm 1$ \\
Sodium fluoride 20 mg/kg+Taurine 3g/kg after 4 week & $13 \pm 5.0$ & $159 \pm 74^{\mathrm{b}}$ & $0.07 \pm 0.03^{\mathrm{b}}$ & $10.8 \pm 4^{\mathrm{ab}}$ & $6.6 \pm 3$ \\
\hline
\end{tabular}

Each group consists of 6 animals. *Represents the significant difference from the control group when $\mathrm{P}<0.05$. a represents the presence of a significant difference from the sodium fluoride group after 2 weeks of treatment. $\mathrm{b}$ represented a significant difference from the sodium fluoride group after 4 weeks of treatment. A, there was a significant difference from the group of sodium fluoride after 2 weeks of treatment. Mean \pm standard error.

Table 4: Malondialdehyde concentrations after 2 and 4 weeks of treatment with $\mathrm{NaF}$ and taurine alone or in combination

\begin{tabular}{lcc}
\hline Groups & MDA nmol/L, after 2week & MDA nomol/L, after 4week \\
\hline Control & $11.1 \pm 2$ & $11 \pm 3$ \\
Sodium fluoride $20 \mathrm{mg} / \mathrm{kg}$ & $12.9 \pm 3^{*}$ & $13.4 \pm 2^{*}$ \\
Taurine $3 \mathrm{~g} / \mathrm{kg}$ & $11.02 \pm 3$ & $11.8 \pm 2^{\mathrm{a}}$ \\
Sodium fluoride $20 \mathrm{mg} / \mathrm{kg}$ and Taurine $3 \mathrm{~g} / \mathrm{kg}$ & $11.3 \pm 2$ & $11.9 \pm 3^{\mathrm{a}}$ \\
\hline
\end{tabular}

Each group consists of 8 animals. *Represents the significant difference from the control group when $\mathrm{P}<0.05$. a, represented a significant difference from the sodium fluoride group after 2 and 4 weeks of treatment. Mean \pm standard error.

Table 5: Glutathione concentrations after two and four weeks of treatment with $\mathrm{NaF}$ and taurine alone or together

\begin{tabular}{lcc}
\hline Groups & GSH nmol/L, after 2week & GSH nmol/L, after 4week \\
\hline Control & $0.024 \pm 0.01$ & $0.026 \pm 0.009$ \\
Sodium fluoride $20 \mathrm{mg} / \mathrm{kg}$ & $0.012 \pm 0.005^{*}$ & $0.010 \pm 0.002^{*}$ \\
Taurine $3 \mathrm{~g} / \mathrm{kg}$ & $0.03 \pm 0.01^{\mathrm{a}}$ & $0.03 \pm 0.01^{\mathrm{a}}$ \\
Sodium fluoride $20 \mathrm{mg} / \mathrm{kg}$ and Taurine $3 \mathrm{~g} / \mathrm{kg}$ & $0.025 \pm 0.01^{\mathrm{a}}$ & $0.035 \pm 0.02^{\mathrm{a}}$ \\
\hline
\end{tabular}

Each group consists of 6 animals and the data is in the form of a mean and standard error. The group consists of 6 chicks. *Represents the significant difference from the control group when $\mathrm{P}<0.05$. a, represented a significant difference from the sodium fluoride group after 2 and 4 weeks of treatment.

Histopathological results of chicken liver of $\mathrm{NaF}$ group shows loss of architecture of hepatic tissue characterized by coagulative necrosis of hepatocytes, dilation of sinusoids, congestion of sinusoids (Figure 1) shows loss of architecture of hepatic tissue characterized by coagulative necrosis of hepatocytes, dilation of sinusoids, and congestion of central vein and sinusoids (Figure 2). photomicrograph of chicken brain of $\mathrm{NaF}$ group shows severe vacuolation, congestion of blood vessels and gliosis (Figure 3), also shows severe vacuolation, vasogenic edema, congestion of blood vessels and gliosis (Figure 4). Kidney of $\mathrm{NaF}$ group shows nephritis representing by 
infiltration of inflammatory cells, necrosis of epithelial cells lining renal tubules, atrophy of glomeruli and dilation of Bowman's space, congestion of blood vessels and hemorrhage (Figure 5).

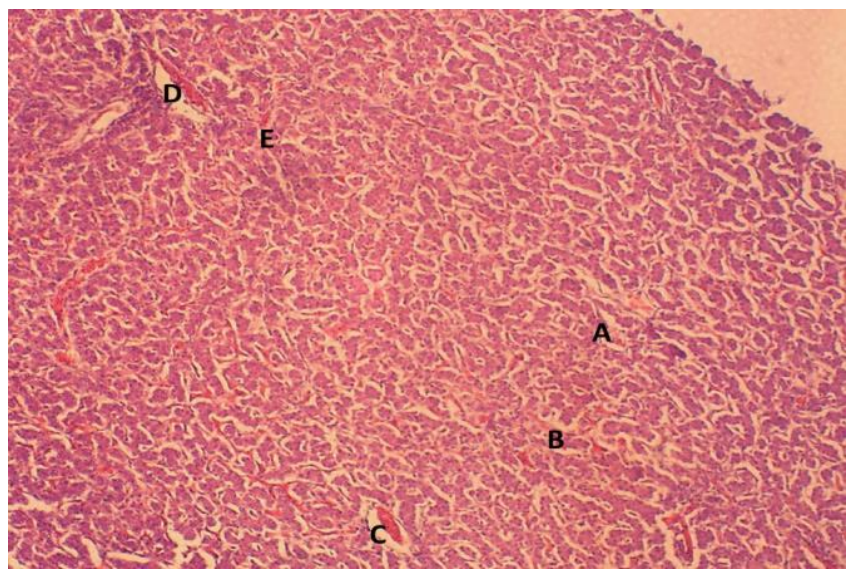

Figure 1: photomicrograph of chicken liver of $\mathrm{NaF}$ group (for 4 weeks) shows loss of architecture of hepatic tissue characterized by coagulative necrosis of hepatocytes (A), dilation of sinusoids (B), congestion of sinusoids (C), central (D) and portal vein (E). H\&E stain, 100X.

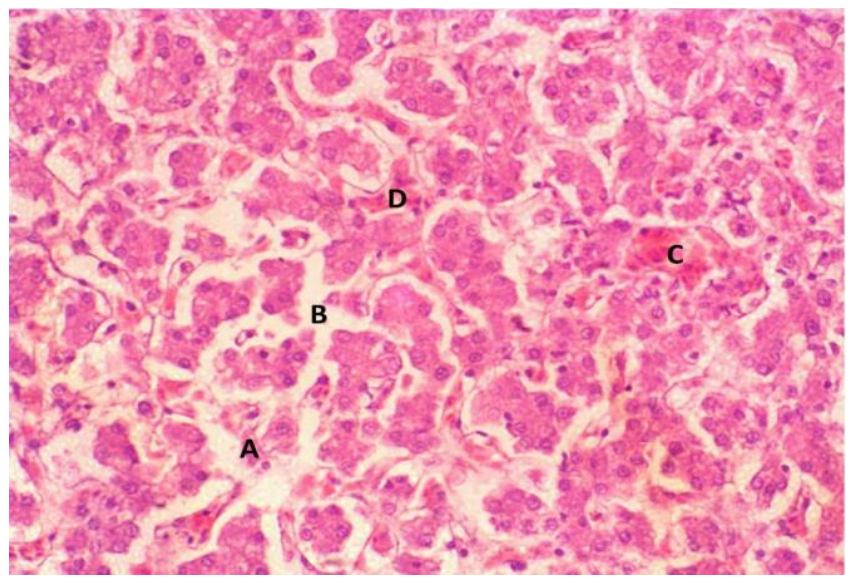

Figure 2: photomicrograph of chicken liver of $\mathrm{NaF}$ group (for 4 weeks) shows loss of architecture of hepatic tissue characterized by coagulative necrosis of hepatocytes (A), dilation of sinusoids (B) and congestion of central vein (C) and sinusoids (D). H\&E stain, 400X.

After two weeks of treatment, a histological section of the chick's liver of the group treated with sodium fluoride with taurine revealed normal histological parameters represented by hepatocytes, sinuses, and central vein (Figure 6). Histological section of the brain of the group, treated with sodium fluoride with taurine, a normal cerebral cortex represented by neurons, glial follicles, and a normal cerebral cortex represented by neurons, glial cell (Figure 7).
Renal glomerulus, proximal renal tubules, and distal renal tubules of chicks treated with sodium fluoride with taurine showed normal histopathology of the kidneys, represented by the renal glomerulus, proximal renal tubules, and distal renal tubules (Figure 8). The cerebral cortex, constituted by neurons, glial cells, and blood vessels, appeared normal in the group treated with taurine alone after four weeks (Figure 9). The histological section of the kidney in the group treated with sodium fluoride with taurine after 4 weeks of treatment reveals slight expansion of Bowman's capsule in the renal glomerulus and slight cellular swelling of the proximal renal tubules and distal renal tubules (Figure 10), brain of sodium fluoride with Taurine treated group shows normal architecture of brain tissue (Figure 11) and the histological section of the kidney in the group treated with sodium fluoride with taurine after 4 weeks of treatment shows the slight expansion of Bowman's capsule in the renal glomerulus (Figure 12).

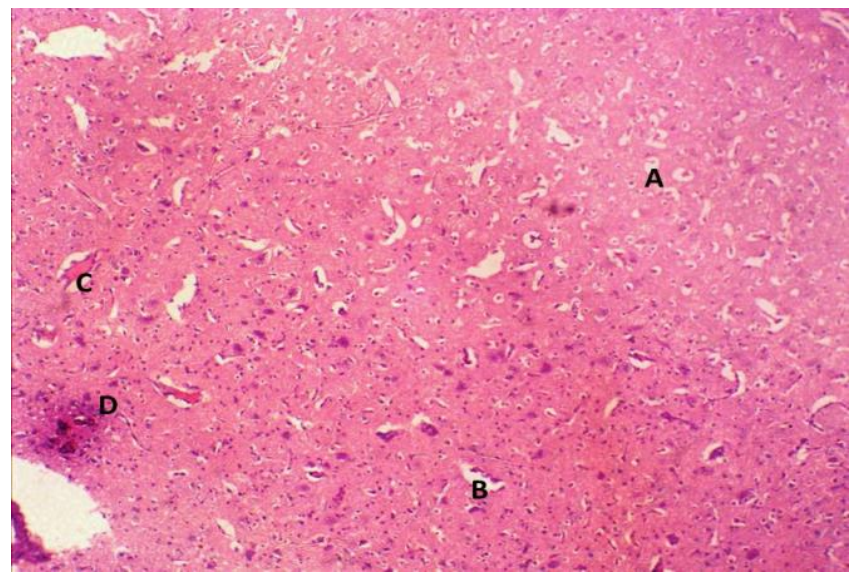

Figure 3: photomicrograph of chicken brain of $\mathrm{NaF}$ group (for 4 weeks) shows severe vacuolation (A), congestion of blood vessels (B) and gliosis (C). H\&E stain, 100X.

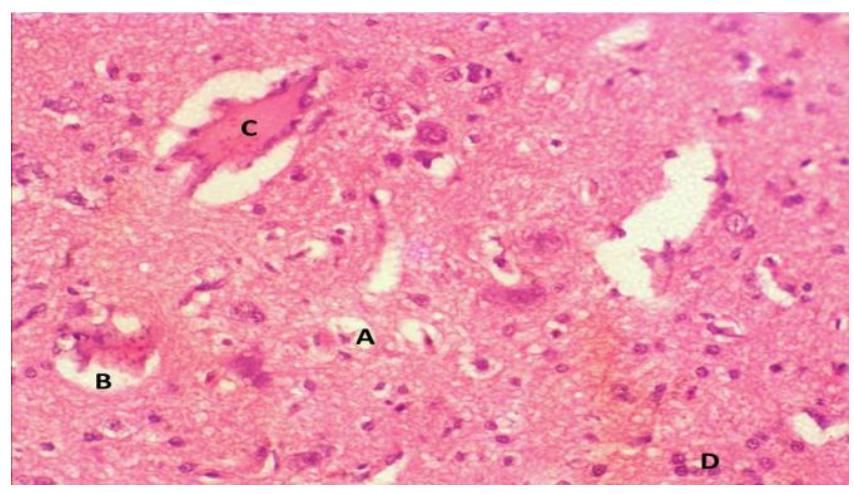

Figure 4: photomicrograph of chicken brain of $\mathrm{NaF}$ group (for 4 weeks) shows severe vacuolation (A), vasogenic edema (B), congestion of blood vessels (C) and gliosis (D). H\&E stain, 400X. 


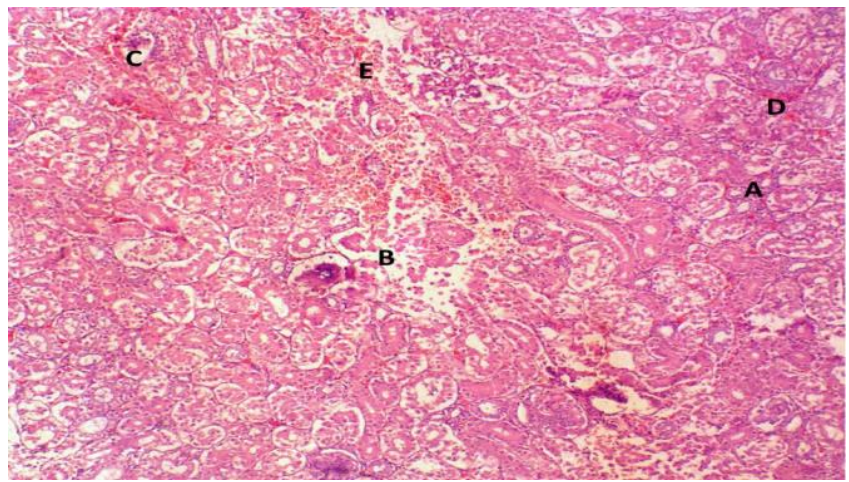

Figure 5: photomicrograph of chicken kidney of $\mathrm{NaF}$ group (for 4 weeks) shows nephritis representing by infiltration of inflammatory cells (A), necrosis of epithelial cells lining renal tubules (B), atrophy of glomeruli and dilation of Bowman's space (C), congestion of blood vessels (D) and hemorrhage (D). H\&E stain, 100X.

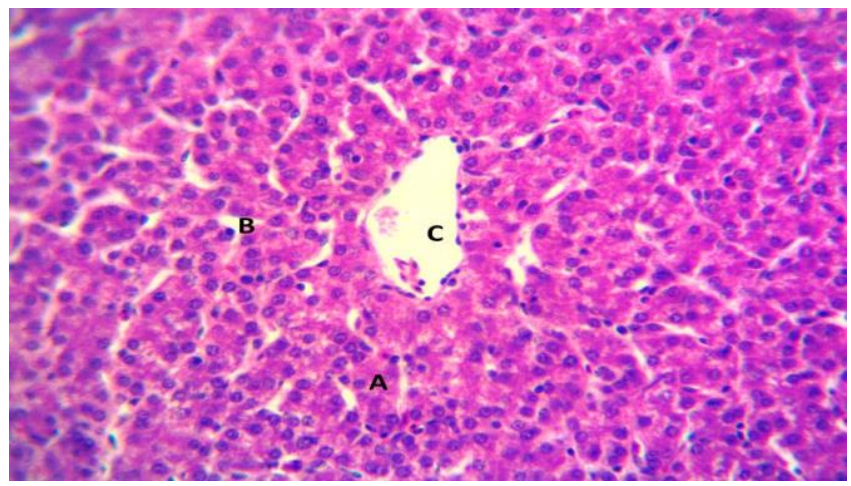

Figure 6: photomicrograph of liver of sodium fluoride with Taurine treated group ( 2 weeks) shows normal architecture of liver tissue characterized by hepatocytes (A), sinusoids (B) and central vein (C). H\&E stain, 400X.

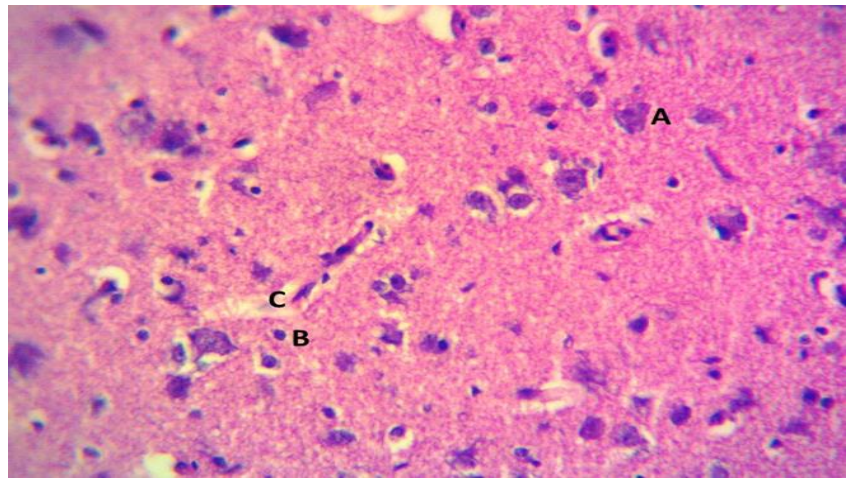

Figure 7: photomicrograph of brain of sodium fluoride with Taurine treated group ( 2 weeks) shows normal architecture of brain tissue characterized by nerve cells (A), glial cells (B) and blood vessels (C). H\&E stain, 100X.

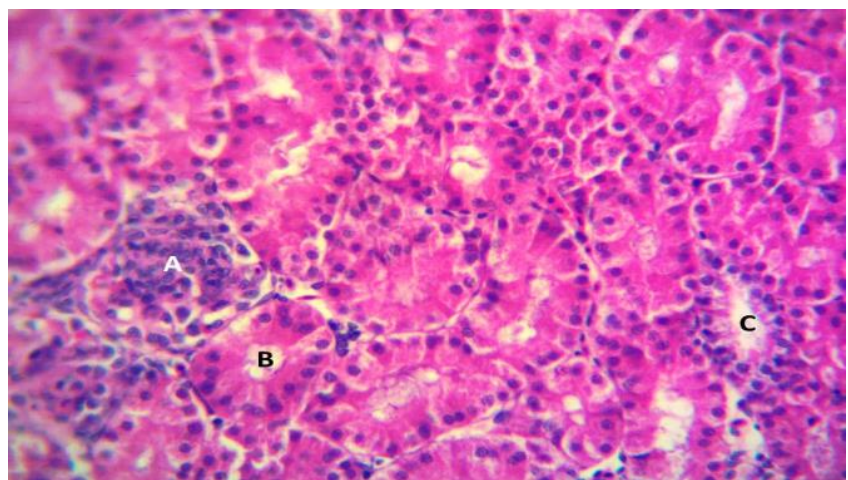

Figure 8: photomicrograph of kidney of sodium fluoride with Taurine treated group ( 2 weeks) shows presene of the normal architecture of renal tissue of kidney characterized by renal glomeruli (A), proximal renal tubules (B) in addition to presence in the distal renal tubules (C). H\&E stain, 400X.

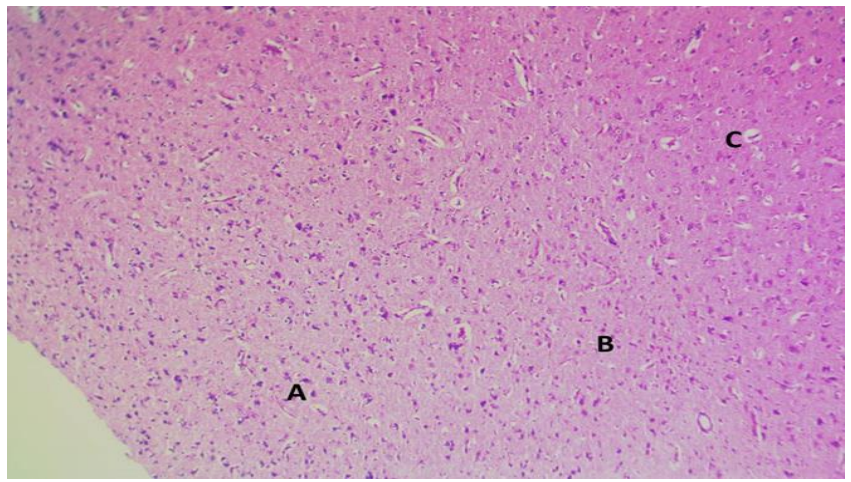

Figure 9: photomicrograph of brain of Taurine treated group (4 weeks) shows normal architecture of brain tissue characterized by nerve cells (A), glial cells (B) and blood vessels (C). H\&E stain, 100X.

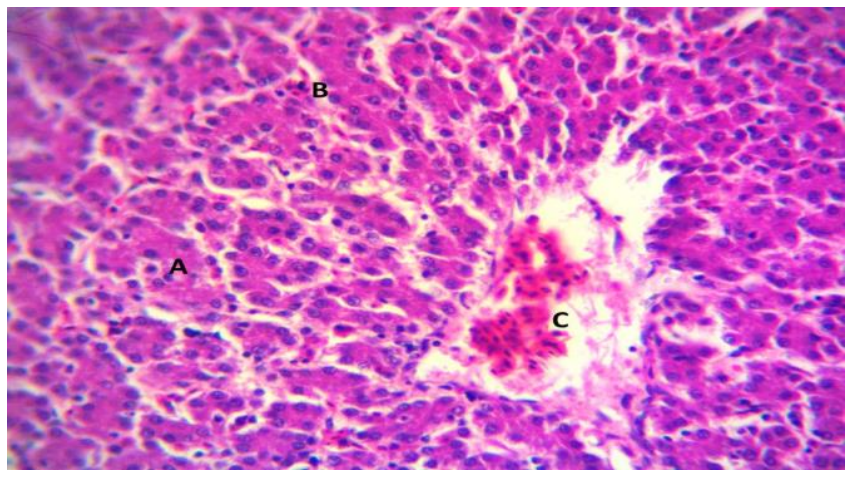

Figure 10: photomicrograph of liver of sodium fluoride with Taurine treated group (4 weeks) shows normal architecture of liver tissue characterized by hepatocytes (A) with mild congestion if sinusoids (B) and central vein (C). H\&E stain, 400X. 


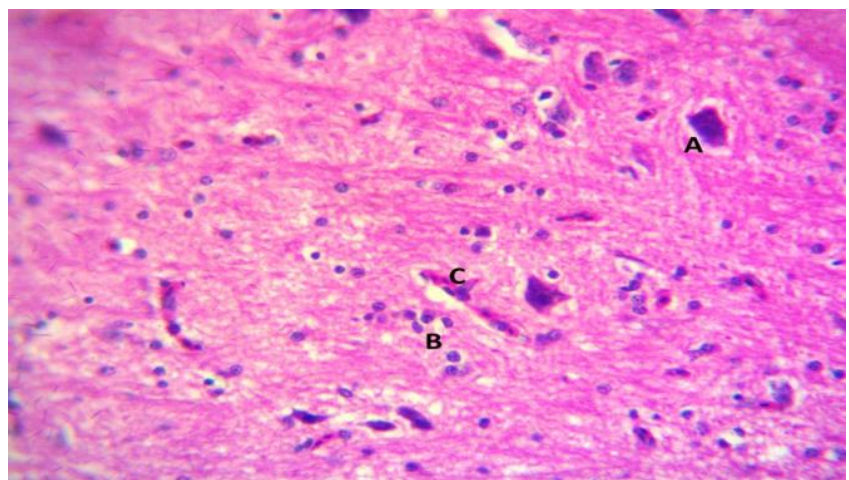

Figure 11: photomicrograph of brain of sodium fluoride with Taurine treated group (4 weeks) shows normal architecture of brain tissue characterized by nerve cells (A) with mild gliosis (B) and mild congestion of blood vessels (C). H\&E stain, 400X.

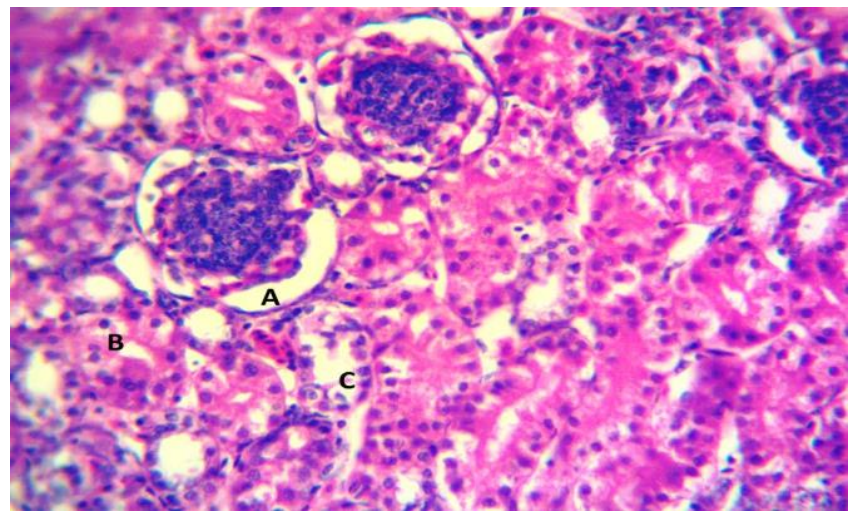

Figure 12: photomicrograph of kidney of sodium fluoride with Taurine treated group (4 weeks) shows mild dilation of Bowman's space in renal glomeruli (A), mild cell swelling of epithelial cells lining proximal renal tubules (B) and distal renal tubules (C). H\&E stain, 400X.

\section{Discussion}

Taurine is the primary sulfur-containing amino acid found intracellularly in most mammalian tissues, and it has antioxidant properties that regulate exudative calcium and intracellular calcium flow, as well as some cellular protective properties $(1,4)$.

The ability of taurine as an antioxidant to affect the stability of the cellular membrane and scavenge free radicals ROS, as well as reduce the damage caused by oxidation is attributed to its ability to affect the stability of the cellular membrane and scavenge free radicals ROS, and reduce the damage caused by oxidation (2), our study confirmed these effects through the results recorded when treated with taurine after two and four weeks of its use as a sodium fluoride toxicity treatment.
Sodium fluoride caused motor inhibition in the open field test and increased rest time in the tonic immobility test. Taurine is very important in brain development and is distributed in the cerebellum, cortex, and hippocampus, according to studies performed on mice and zebrafish. Taurine is also effective against the mechanisms associated with stress. The hypothalamic-pituitary-adrenal axis (HPA) is inhibited, which may be resulting in these effects (1).

Taurine also inhibits the overproduction of glutamate by preventing the reduction of serotonin, dopamine, noradrenaline, and acetylcholine levels in mice subjected to chronic stress (4).

Excessive fluoride exposure causes neurotoxicity in both humans and animals, according to epidemiological and experimental studies one of these study found that taurine's antidepressant effect is mediated by increased mRNA expression in the hippocampus (5).

Through the oxidation of fats and proteins, as well as DNA damage, oxidative stress causes nerve cell damage and death (15). glutathione is an essential cellular defense against activated oxygen free radicals, and it is one of the most significant antioxidants that form the first line of defense against oxidative stress in cells (12).

It led to a better understanding of the underlying mechanisms of taurine's neuroprotective role in the brain, as taurine increased glutathione levels after sodium fluoride decreased them in the serum, which in turn reduced malondialdehyde peroxidation in chicken serum treated with sodium fluoride and treated with taurine after 2 and 4 weeks. As a result, this finding was in line with another rat study that found taurine to be an antioxidant that protects rat liver cells from sodium fluoride-induced cytotoxicity (16).

These findings led us to believe that taurine's neurotoxic mechanism against sodium fluoride-induced brain neurotoxicity is partially due to its ability to enhance the antioxidant defense system and thus prevent the formation and accumulation of lipid peroxidation in taurine-treated chicks.

A histological examination of the brain confirmed this conclusion, with histological sections revealing that chicks treated with taurine had relative healing in brain tissue when compared to chicks treated with sodium fluoride alone.

Because the liver is the primary organ responsible for metabolism and participates in the metabolism of toxic compounds produced during operations, measuring liver function enzymes ALT and AST provides a clear indication of the effect of liver function and the extent of improvement in its levels, suggesting a role for taurine in repairing liver damage. Toxins enter living organisms from the environment, both systemic and exogenous (17).

Toxins can easily interrupt the metabolism process because the liver is the main site for microorganism detoxification. The liver's toxic effect is typically 
manifested by disruptions in cellular respiration that interfere with oxidation and reduction mechanisms, either through impairment in protein, carbohydrate, and fat metabolism or by disruptions in liver transport (18). Because sodium fluoride causes hepatotoxicity, the effect of liver cells in animals treated with it in our study could be explained by this.

These findings were made using hepatic tissue sections, which revealed a toxic effect on the liver tissue of chicks given sodium fluoride, while the pathological effects in chicks given taurine improved. Taurine may play a role in reducing inflammation by lowering cytokine levels (19).

Creatinine is one of the indicators of kidney function, and our research found that taurine increased its level in serum when compared to chicken serum treated with sodium fluoride. This finding is consistent with many studies performed on birds and mice, which found that when kidney damage occurs, creatinine levels increase, the level of creatinine was associated with the induced renal tissue damage (20), where the kidneys are the target organ for toxic foreign biomaterials due to their ability to extract and concentrate toxic substances by highly specialized cells and also due to the extensive blood flow (about $21 \%$ of the cardiac output) (21).

The histopathological effects improved after treatment with taurine, where the improvement was visible in the histological parts of the chicks. With sodium fluoride, renal excretion of fluoride is considered one of the most important mechanisms for regulating fluoride levels in the body, and the histopathological effects improved after treatment with taurine because renal excretion of fluoride is considered one of the most important mechanisms for regulating fluoride levels in the body.

The appearance of pathological tissue changes in the liver and kidneys may be due to hepatic and renal oxidative stress and pathological changes caused by the effects of sodium fluoride treatment. Other studies on catfish, Heteropneustis fossils, found that exposure to $35 \mathrm{mg} / \mathrm{liter}$ fluoride in water for 45 days and $70 \mathrm{mg} /$ liter fluoride in water for 90 days caused renal degeneration, enlargement of the epithelial cells of the renal tubules, and expansion of the glomeruli (22).

The generation of free radicals by fluoride may be the cause of these changes in the structure of the kidneys. Fluoride has also increased capillary permeability by affecting the connected units between the vascular endothelium of veins and capillaries (23).

The loss of prostaglandin PGE2's vasodilating effect on the arteries adjacent to the nucleus, as well as the dilation of the urinary spaces (24), maybe the result of high pressure across the capillaries in the glomeruli.

The renal tubules of chicks treated with sodium fluoride exhibited significant degenerative lesions, which is acceptable because the renal tubules are especially sensitive to toxic effects because they require large amounts of oxygen and have compatible transport mechanisms that can transport toxins and may be damaged by this process (16).

Glutathione is one of the most important cellular antioxidants in the liver, Cysteine can decrease oxidative stress and cell injury in alcohol-treated rats by inhibiting lipid peroxidation, according to one study this research backed up our current findings, which showed that a decrease in glutathione levels was linked to an increase in MDA levels in the blood (9).

Taurine supplementation, on the other hand, avoids a decrease in total thiol content by preventing the free radical attack in cells that contain proteins and fats taurine is effective at preserving the - $\mathrm{SH}$ (sulfhydryl) groups which are required for many amino acid structural functions, particularly cysteine this promotes glutathione synthesis and may help explain why sodium fluoride treatment reduces oxidative damage. As a result, some studies have found a link between taurine administration and GSH synthesis, with taurine assisting in the development of GSH synthesis and antioxidant defense in cells (22).

The level of calcium in sodium fluoride poisoning is critical because it affects its metabolism as well as the effect on its connections, as evidenced by its high level when treated with it, which improved significantly when combined with taurine, which affects the calcium pathways and their organization, is associated with it, and regulates its cell flow (20).

According to all of the above, taurine provides its protective properties through various mechanisms, including osmotic regulation, antioxidants, stabilization and stabilization of the cell membrane, removal of biotic toxins, inhibition of fibrosis, protection of mitochondria, control of apoptosis, modulation of bile acid conjugation and antiinflammatory effect (25).

\section{Conclusion}

We conclude from this study that taurine has a clear therapeutic effect against oxidative stress, as evidenced by behavioral and motor behavioral effects, as well as levels of glutathione, malondialdehyde, and liver function enzymes ALT, AST, and serum creatinine, as well as histopathological examination of the brain, kidneys, and liver.

\section{Acknowledgment}

The research was supported by the College of Veterinary Medicine, University of Mosul.

\section{Conflict of interest}

There is no conflict of interest 


\section{Reference}

1. Lv Q, Yang Q, Cui Y, Yang J, Wu G, Liu M, Ning Z, Cao S, Dong G, $\mathrm{Hu}$ J. Effects of Taurine on ACE, ACE2, and HSP70 expression of the hypothalamic-pituitary-adrenal axis in stress-induced hypertensive rats. Taurine. 2017:871-886. DOI: 10.1007/978-94-024-1079-2_69

2. Jangra A, Rajput P, Dwivedi DK, Lahkar M. Amelioration of repeated restraint stress-induced behavioral deficits and hippocampal anomalies with taurine treatment in mice. Neurochem Res. 2020;45(4):731-40. DOI: $10.1007 / \mathrm{s} 11064-019-02945-8$

3. Scriba MF, Gasparini J, Jacquin L, Mettke-Hofmann C, Rattenborg $\mathrm{NC}$, Roulin A. The effect of food quality during growth on spatial memory consolidation in adult pigeons. J Exp Biol. 2017;220(4):57381. DOI: $10.1242 /$ jeb. 152454

4. Hezzomo NJ, Silveira A, Giuliani GS, Quadros VA, Rosemberg DB. The role of taurine on anxiety-like behaviors in zebrafish: a comparative study using the novel tank and the light-dark tasks. Neurosci Let. 2016;613:19-24. DOI: 10.1016/j.neulet.2015.12.037

5. Jakaria M, Azam S, Haque ME, Jo SH, Uddin MS, Kim IS, Choi DK. Taurine and its analogs in neurological disorders: Focus on therapeutic potential and molecular mechanisms. Redox Biol. 2019;24:101223. DOI: 10.1016/j.redox.2019.101223

6. Adedara IA, Olabiyi BF, Ojuade TD, Idris UF, Onibiyo EM, Farombi EO. Taurine reverses sodium fluoride-mediated increases in inflammation, caspase- 3 activity, and oxidative damage along the brain-pituitary-gonadal axis in male rats. Canadian $\mathrm{J}$ Physiol Pharmacol. 2017;95(9):1019-29. DOI: 10.1139/cjpp-2016-0641

7. Shirakami Y, Lee SA, Clugston RD, Blaner WS. Hepatic metabolism of retinoids and disease associations. Biochem Mol Cell Biol Lipids. 2012;1821(1):124-36. DOI: $10.1016 /$ i.bbalip.2011.06.023

8. Su Y, Fan W, Ma Z, Wen X, Wang W, Wu Q, Huang H. Taurine improves functional and histological outcomes and reduces inflammation in traumatic brain injury. Neurosci. 2014;266:56-65. DOI: $10.1016 /$ j.neuroscience.2014.02.006

9. Mullens W, Damman K, Testani JM, Martens P, Mueller C, Lassus J, Tang WW, Skouri H, Verbrugge FH, Orso F, Hill L. Evaluation of kidney function throughout the heart failure trajectory-a position statement from the Heart Failure Association of the European Society of Cardiology. Euro J Heart Failure. 2020;22(4):584-603. DOI: 10.1002/ejhf.1697

10. Kules J, Bilic P, Ljubic BB, Gotic J, Crnogaj M, Brkljacic M, Mrljak V. Glomerular and tubular kidney damage markers in canine babesiosis caused by Babesia Canis. Ticks Dis. 2018;9(6):1508-17. DOI: $10.1016 / \mathrm{j}$. ttbdis.2018.07.012

11. Abdullah R A, Taee F D, Thanoon I A. Effect of levofloxacin on some body tissues in mice. Iraqi J Vet Sci. 2021;35(1):109-111. DOI: 10.33899/ijvs.2020.126416.1316

12. Kabir H, Gupta AK, Tripathy S. Fluoride and human health: Systematic appraisal of sources, exposures, metabolism, and toxicity. Crit Rev Environ Sci Technol. 2020;50(11):1116-93. DOI: 10.1080/10643389.2019.1647028

13. Al-khafaf A, Ismail H Kh, Alsaidya A MA. Histopathological effects of experimental exposure to lead on nervous system in albino female rats. Iraqi J Vet Sci. 2021;35(1):45-48. DOI: 10.33899/ijvs.2019.126248.1273

14. Buege JA, Aust SD. Microsomal lipid peroxidation. 1978;52:302-310. DOI: 10.1016/S0076-6879(78)52032-6

15. Onyegeme-Okerenta BM, Amadi BA, Ezeonyilimba VO. The ameliorating potential of Annona muricata on sodium fluorideinduced toxicity on liver and kidney of male Wistar rats. J Compl Alter Med Res. 2018;12:1-7. DOI: 10.9734/JOCAMR/2018/43274

16. Ekambaram M, Itthagarun A, King NM. Ingestion of fluoride from dentifrices by young children and fluorosis of the teeth-a literature review. J Clin Pediat Dentist. 2011;36(2):111-22. DOI: 10.17796/jcpd.36.2.3106602470287130

17. Qing-Feng S, Ying-Peng X, Tian-Tong X. Matrix metalloproteinase-9 and $\mathrm{p} 53$ are involved in chronic fluorosis-induced blood-brain barrier damage and neurocyte changes. Arch Med Sci. 2019;15(2):457. DOI: 10.5114/aoms.2019.83294

18. Netti V, Pizzoni A, Pérez-Domínguez M, Ford P, Pasantes-Morales H, Ramos-Mandujano G, Capurro C. Release of taurine and glutamate contributes to cell volume regulation in human retinal Müller cells: differences in modulation by calcium. J Neurophysiol. 2018;120(3):973-84. DOI: 10.1152/jn.00725.2017

19. Chiba H, Seo Y, Sai S, Namekawa M, Ishizu T, Aonuma K. Renoprotective effects of tolvaptan in hypertensive heart failure rats depend on renal decongestion. Hypertension Res. 2019;42(3):319-28. DOI: $\underline{10.1038 / \mathrm{s} 41440-018-0169-3}$

20. Wagoner MP, Yang Y, McDuffie JE, Klapczynski M, Buck W, Cheatham L, Eisinger D, Sauce F, Lynch KM, Sonee M, Ma JY. Evaluation of temporal changes in urine-based metabolomic and kidney injury markers to detect compound-induced acute kidney tubular toxicity in beagle dogs. Curr Topics Med Chem. 2017;17(24):2767-80. DOI: 10.2174/1568026617666170713172331

21. Gunatilake S, Seneff S, Orlando L. Glyphosate's synergistic toxicity in combination with other factors as a cause of chronic kidney disease of unknown origin. Inter J Environ Res Public Hlth. 2019;16(15):2734. DOI: 10.3390/ijerph16152734

22. Guan ZZ, Wang YN, Xiao KQ, Dai DY, Chen YH, Liu JL, Sindelar $\mathrm{P}$, Dallner G. Influence of chronic fluorosis on membrane lipids in rat brain. Neurotoxicol Teratol. 1998;20(5):537-42. DOI: 10.1016/S08920362(97)00136-0

23. Goc Z, Kapusta E, Formicki G, Martiniakova M, Omelka R. Effect o taurine on ethanol-induced oxidative stress in mouse liver and kidney. Chinese J Physiol. 2019;62(4):148. DOI: 10.4103/CJP.CJP_28_19

24. Alabdaly YZ, Al-Hamdany EK, Abed ER. Toxic effects of butylated hydroxytoluene in rats. Iraqi J Vet Med. 2021;35(1):121-8. DOI: 10.33899/ijvs.2020.126435.1322

25. Al-abdaly YZ, Saeed MG, Al-Hashemi HM. Effect of methotrexate and aspirin interaction and its relationship to oxidative stress in rats. Iraqi J Vet Med. 2021;35(1):151-6. DOI: 10.33899/ijvs.2020.126490.1335

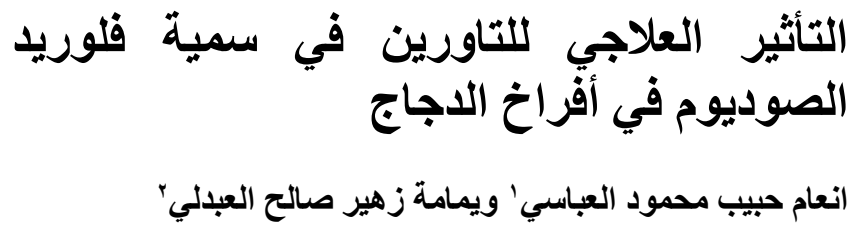

'وزارة الزراعة العراقية، مديرية زراعة نينوى، كائهة الفرع الفسلجة

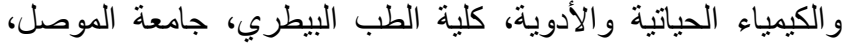
الموصل، العراق التيات الخلاصة

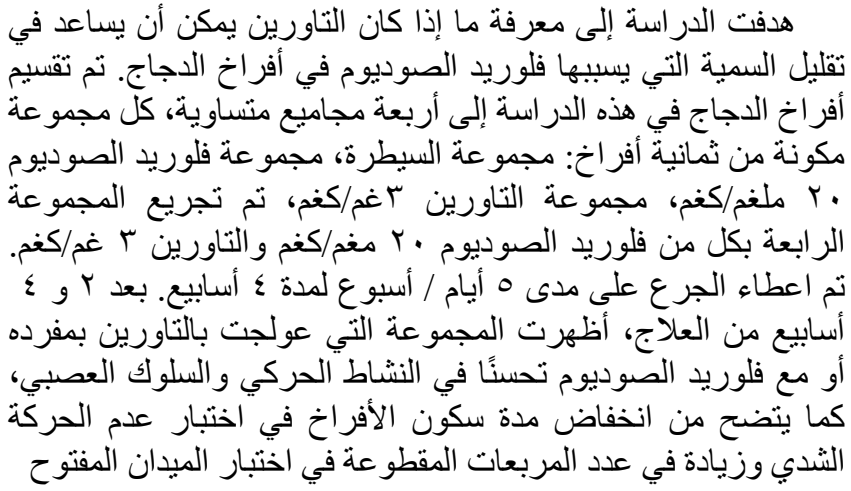




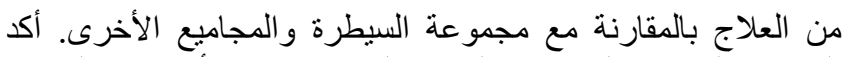

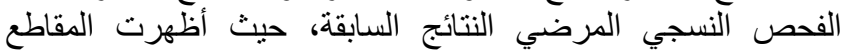

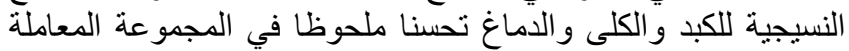

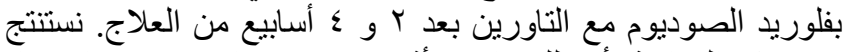

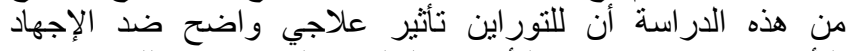

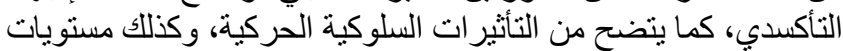

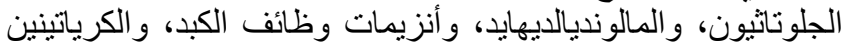

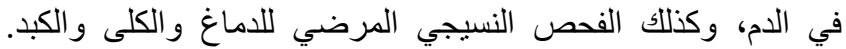

مقارنة بالمجموعة المعالجة بفلوريد الصوديوم لوحده. زاد مستوى الإي

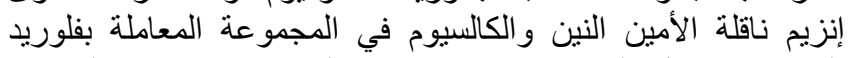

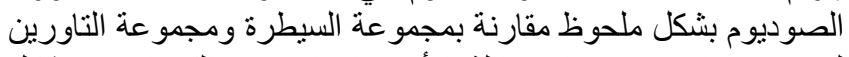

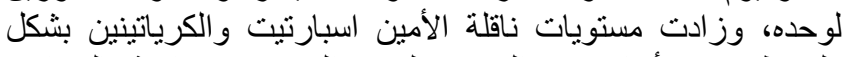

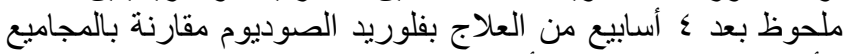

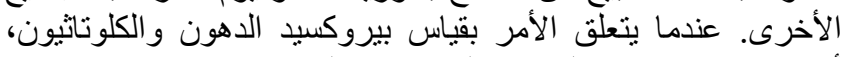

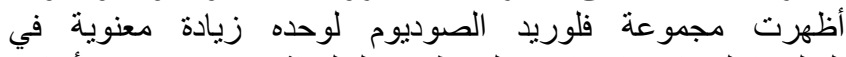
المالوندايالديهايد و انخفاض ملحوظ في الجلوناثيون بعد ب و ـ ع أسابيع في 